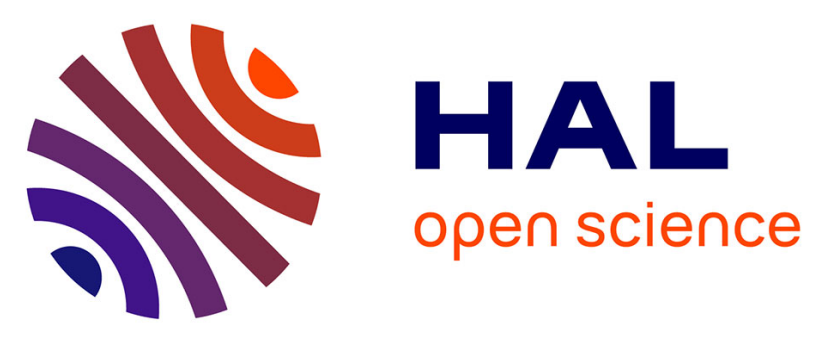

\title{
Analysis of the structural changes of a pellet/powder bentonite mixture upon wetting by X-ray computed microtomography
}

Agustín Molinero Guerra, Patrick Aimedieu, Michel Bornert, Yu-Jun Cui, Anh Minh A.M. Tang, Zhao Sun, Nadia Mokni, Pierre Delage, Frédéric Bernier

\section{To cite this version:}

Agustín Molinero Guerra, Patrick Aimedieu, Michel Bornert, Yu-Jun Cui, Anh Minh A.M. Tang, et al.. Analysis of the structural changes of a pellet/powder bentonite mixture upon wetting by X-ray computed microtomography. Applied Clay Science, 2018, 165, pp.164-169. 10.1016/j.clay.2018.07.043 . hal-02130370

\section{HAL Id: hal-02130370 \\ https://hal-enpc.archives-ouvertes.fr/hal-02130370}

Submitted on 15 May 2019

HAL is a multi-disciplinary open access archive for the deposit and dissemination of scientific research documents, whether they are published or not. The documents may come from teaching and research institutions in France or abroad, or from public or private research centers.
L'archive ouverte pluridisciplinaire HAL, est destinée au dépôt et à la diffusion de documents scientifiques de niveau recherche, publiés ou non, émanant des établissements d'enseignement et de recherche français ou étrangers, des laboratoires publics ou privés.

\section{(1) (1) $\$$}

Distributed under a Creative Commons Attribution - NonCommercial - NoDerivatives 44.0 
3

4

\title{
Analysis of the structural changes of a pellet/powder bentonite mixture upon wetting by $X$-ray computed microtomography
}

\author{
Agustín Molinero Guerra ${ }^{1,2}$, Patrick Aimedieu ${ }^{1}$, Michel Bornert ${ }^{1}$, Yu-Jun Cui ${ }^{1}$, Anh Minh
} Tang $^{1 *}$, Zhao Sun $^{3}$, Nadia Mokni ${ }^{2}$, Pierre Delage ${ }^{1}$, Frédéric Bernier ${ }^{4}$

${ }^{1}$ Ecole des Ponts ParisTech, CNRS, IFSTTAR, Laboratoire Navier/CERMES, Marne La Vallée, France

${ }^{2}$ Institut de Radioprotection et de Sûreté Nucléaire (IRSN), Fontenay-aux-Roses, France

${ }^{3}$ Tongji University, China

${ }^{4}$ Agence Fédérale de Contrôle Nucléaire (AFCN), Belgium

*Corresponding author

Dr. Anh Minh Tang

Ecole des Ponts ParisTech

6-8 av. Blaise Pascal

Cité Descartes, Champs-sur-Marne

77455 Marne la Vallée

France

E-mail: anhminh.tang@enpc.fr 


\section{Abstract:}

Pellet/powder bentonite mixture is one of the candidate materials for sealing plugs in deep geological high-level radioactive waste disposal. This note presents an investigation on the structure changes of this mixture occurring during the saturation process by means of X-ray computed micro-tomography. The test was performed in an infiltration column $(60 \mathrm{~mm}$ in inner diameter and $120 \mathrm{~mm}$ in height). Water was supplied to the two ends of the column and the changes of the sample morphology were observed during a period of 100 days of hydration. Digital Volume Correlation (DVC) technique was used to determine the vertical displacement field of the bentonite powder. A pressure transducer was used to measure the axial swelling pressure during the hydration. The results show that the initial distribution of powder in the inter-pellet pores was not homogeneous; the powder filled almost completely the pores in the zones close to the two ends while air-filled inter-pellet voids were observed in the middle of the column specimen. When water started to infiltrate inside the specimen from both ends, the pellets and the powder grains started to swell (because of the swelling properties of smectite, the principal mineral of bentonite) and filled the voids. That induced at the same time increase of swelling pressure and downward movement of powder grains. The results allowed a better understanding on the hydro-mechanical couplings, at the pellet scale, in the pellet/powder bentonite mixture upon wetting.

Keywords: pellet/powder bentonite mixture; X-ray computed microtomography; initial heterogeneity; Digital Volume Correlation; water saturation; homogenization. 
In the context of deep geological high-level radioactive waste disposal, non-compacted pellet/powder bentonite mixtures are considered as candidate sealing materials because of their high swelling capacity and high radionuclide migration retardation properties, as well as their operational advantages: they are easy to transport, install, and allow gaps between the rock and the seal to be minimized. In a real repository this unsaturated mixture will be installed to plug galleries. Then, water coming from the host rock will start saturating the mixture under almost constant-volume conditions. The swollen mixture will fill different voids and generate swelling pressure, ensuring the sealing of the storage system. Molinero Guerra et al. (2017) used X-ray computed tomography (X-ray CT) to investigate the microstructure of pellet/powder bentonite and found that this mixture was characterized by an initial heterogeneous distribution of powder grains inside the inter-pellet pores. This initial state could greatly influence the saturation process and the corresponding structure changes. As a result, the overall hydro-mechanical behavior would change during the saturation process. Therefore, to properly assess the safety of the underground radioactive waste disposal, it is of paramount importance to well understand the microstructure change of the mixture in the course of hydration.

In this context, the Institute of Radioprotection and Nuclear Safety (IRSN, France), as a part of the overall research and development program that aims at providing scientific background for disposal safety, launched the SEALEX (SEALing performance EXperiments) project, within which this work was conducted. It consists of a series of full-scale experiments carried out in IRSN's Underground Research Laboratory (URL - Tournemire, France) (Barnichon \& Deleruyelle, 2009; Mokni \& Barnichon, 2016) and small-scale experiments conducted in the laboratory (Wang et al., 2012; Saba et al., 2014). One of the aims of the full-scale experiments was to test the long-term hydraulic performance of sealing systems in normal conditions for 
different clay core compositions (pure bentonite or bentonite/sand mixtures) and conditionings (pre-compacted blocks, mixture of pellets/powder, or in-situ compacted). In the present work, a pellet/powder bentonite mixture with a proportion of $80 / 20$ in dry mass was investigated.

The hydro-mechanical behavior of engineered barriers composed of compacted bentonite/sand mixtures or compacted pure bentonite has been extensively investigated (e.g. Pusch 1982; Graham et al., 1989; Komine \& Ogata, 1994; Dixon et al., 1996; Alonso et al., 2005; Wang et al., 2013b, 2014; Saba et al., 2014; Sun et al., 2014). However, few studies have been carried out on the mixture of pellet and powder of bentonite. Imbert \& Villar (2006) performed infiltration tests on a pellet/powder bentonite mixture and found that the swelling pressure was analogous to that of a specimen of compacted powder at the same dry density. Garcia-Siñeriz et al. (2015) studied the homogenization process of a material made of bentonite pellets through a large-scale experiment on engineered barrier (EB). Upon dismantling after 12 years of operation, a gradient of density and water content was still found within the mixture because of the initial heterogeneity of the material. Van Geet et al. (2005) investigated the hydration process of a pellet/powder bentonite mixture by X-ray CT. A progressive decrease of the pellets density and an apparent homogenous sample after saturation were observed. However, in the work of Van Geet et al. (2005), a cylindrical cell containing only few pellets was used. As a result, the analyses mainly focused on the scale of a single pellet.

The present work was thus conducted to investigate the structural changes of a pellet/powder bentonite mixture with a large number of pellets by X-ray CT. Firstly, the sealing capacity of the mixture and its structural evolution during saturation were studied. Secondly, Digital Volume Correlation (DVC) technique was applied to calculate the displacement field within the sample. Finally, the evolution of the axial swelling pressure while wetting was 
investigated. The obtained results provide helpful elements to assess the hydromechanical performance of seals/plugs made up of this kind of bentonite mixtures.

\section{Material and methodology}

\subsection{Pellet/powder MX80 bentonite mixture}

The soil studied was a mixture of pellet/powder MX80 bentonite (from Wyoming, USA) at a proportion of $80 / 20$ in dry mass. It was provided by the Laviosa-MPC Company under the commercial name Expangel SP7 for pellets and SP30 for the powder, both were produced from the same bentonite. The bentonite had a smectite content of $80 \%$, other minerals being quartz, calcite and pyrite. The CEC was $98 \mathrm{meq} / 100 \mathrm{~g}$ and the major exchangeable cations were: sodium $(52 \mathrm{cmol}(+) / \mathrm{kg})$, calcium $(37 \mathrm{cmol}(+) / \mathrm{kg})$, magnesium $(10 \mathrm{cmol}(+) / \mathrm{kg})$. The liquid limit was $560 \%$, the plastic limit was $62 \%$ and the unit mass of the solid particles was $2.77 \mathrm{Mg} / \mathrm{m}^{3}$ (Saba et al. 2014).

Cylindro-spherical pellets of bentonite were produced by compacting commercial bentonite powder in a mold of $7 \mathrm{~mm}$ in diameter and $7 \mathrm{~mm}$ in height. The initial suction $(s=135 \pm 3$ MPa) was measured in the laboratory with a chilled mirror dew point tensiometer (Decagon WP4C), corresponding to an initial water content $w=5 \%-7 \%$. The initial void ratio of the pellets was $e=0.306-0.386$ (corresponding to a dry density of $2.00-2.12 \mathrm{Mg} / \mathrm{m}^{3}$ ) and the degree of saturation was $S_{r}=55 \%-66 \%$. The bentonite powder was produced by crushing pellets. An initial water content of $3 \%$ (smaller than that of the pellets) was found in the laboratory, corresponding to an initial suction $s=191 \mathrm{MPa}$ (equally measured by a chilled mirror dew point tensiometer).

The saturation fluid was obtained by mixing the chemical components presented in Table 1 with distilled water until full dissolution. The resulting synthetic water had the same chemical composition as the pore water of the Callovo-Oxfordian claystone (a possible geological host 
rock for radioactive waste disposal in France) from the underground research laboratory in Bure (Wang et al., 2013a). The table shows a total mass of $5.677 \mathrm{~g}$ of salt per liter of solution, that corresponded to a salinity (mass of salt per mass of solution) lower than $1 \%$.

\subsection{Experimental set-up}

A special set-up was designed to carry out X-ray CT observations on the pellet/powder mixture while wetting. The layout is presented in Figure 1a. It consists of a transparent PMMA (PolyMethyl MethAcrylate) cell of $60 \mathrm{~mm}$ in inner diameter and $120 \mathrm{~mm}$ in height (corresponding to $1 / 10$ scale of the SEALEX full-scale experiment). In the full-scale experiment, a horizontal borehole, with a $0.60-\mathrm{m}$ diameter and 5.40-m length was excavated in the Tournemire URL, located in a Mesozoic sedimentary basin on the western edge of the French Causses. The clay-based core, which represented the engineered clay barrier, had a total length of $1.20 \mathrm{~m}$. The laboratory specimen was installed between two porous stones and filter papers, placed at its top and bottom. The constant-volume condition for the pellet/powder bentonite mixture was ensured by the rigid PMMA cell and a top piston which could prevent axial swelling. The mixture was saturated from both sides (top and bottom), simulating the SEALEX in situ experiments (in the full-scale experiment, the clay-based core was saturated with water from both ends with a small pressure of $10 \mathrm{kPa}$ ). The axial swelling pressure was monitored during the test with a force transducer. The base and top were both equipped with a water inlet and an air outlet. Figure 1b shows the PMMA cell positioned inside the X-ray microtomograph. The cell was connected to two reservoirs (located at the top and bottom of the sample) allowing water infiltration. The visualized parameter from X-ray CT observations was the linear attenuation coefficient, which was represented as a grey level. This parameter depended on density, the atomic number and the used X-ray energy.

\subsection{Sample preparation and test protocol}


The pellet/powder mixture was prepared by following the first protocol proposed in Molinero Guerra et al. (2017) to obtain a homogeneous pellet/powder distribution within the sample at the target dry density $\left(1.49 \mathrm{Mg} / \mathrm{m}^{3}\right)$. It consists in filling the cell by packets corresponding to one layer of pellets spread over its base and by adding the corresponding amount of powder (considering the proportion 80-pellet/20-powder in dry mass). The density of the mixture was checked with the mass of the bentonite (with known water content) used to fill the cell (with known volume). Moreover, some reference elements of 1500 PMMA spheres of $1.6 \mathrm{~mm}$ diameter (density $1.18-1.19 \mathrm{Mg} / \mathrm{m}^{3}$ ) were randomly distributed within the sample during the preparation process. The purpose was to carry out quantitative analyses of bentonite powder displacement by DVC technique. DVC is a full-field measurement technique that basically consists in comparing two pictures at two different stages and calculating a displacement field. A detailed description of this technique can be found in Sutton et al. (2009) and Bornert et al. (2012).

The general experiment scheme consisted in scanning the pellet/powder mixture at different times during the saturation process. This resulted in a kind of incremental scans occurring during the hydration process: several X-ray CT observations were carried out at different times until an apparent homogeneous mixture was observed. Each scan took $19 \mathrm{~h}$. Prior to each X-ray CT scan, the whole system shown in Figure 1a was moved and installed inside the microtomograph.

The first step of the test consisted in opening the water inlet valves. Air inside the system was evacuated by opening the air outlet valve until no air bubble could be observed anymore in the outlets. Water was supplied through both the top and bottom of the sample, as in the SEALEX full-scale experiments, during the total time of the test with no pressure. Axial swelling pressure was recorded automatically by a force transducer and a numerical data logger. 


\section{Results}

\subsection{Qualitative analyses}

The behavior of the pellet/powder mixture was firstly investigated by carrying out a qualitative analysis of the X-ray CT observations. Figure 2 shows a vertical section obtained at different times.

Initially, the mixture had a heterogeneous distribution of pellets and powder in spite of a careful preparation procedure. Air-filled inter-pellet voids were dominant in the zone between the bottom and 90-mm height. Above this zone, bentonite powder was more dominant in the inter-pellet voids. The top of the mixture was characterized by the presence of larger air-filled voids between the mixture and the porous stone, most probably due to segregation in the fabrication process. In-depth characterization of a mixture composed of pellet/powder bentonite can be found in Molinero Guerra et al. (2017).

After 2 days of hydration, the voids on the top of the specimen were completely sealed due to their vicinity to the hydration front, so the material at this level swelled quickly. The swelling properties of the material corresponded to the swelling properties of smectite, which was the principal mineral of bentonite. It can be deduced from sections corresponding to 2 days and 4 days after hydration that the evolution of the top hydration front was quicker than the bottom one. Afterwards the evolution of both hydration fronts was similar. The initial structure lost its granular nature while wetting; air-filled inter-pellet voids were still visible after 56 days of hydration, even though the pellets located at the furthest position from both hydration fronts had already swollen at this time. An apparently global homogeneous sample was observed after 100 days of hydration. At this time, almost all the air-filled inter-pellet voids had been completely sealed. In this figure, a glass sphere with a diameter of $10 \mathrm{~mm}$ can be seen; this 
element was introduced to the specimen during its preparation as a reference material for $\mathrm{X}$ ray $\mathrm{CT}$ analysis.

To better understand the transition between the initial state and the final one, an enlargement of a horizontal section at $60 \mathrm{~mm}$ from the bottom hydration front is presented in Figure 3 . Initially, high-density pellets could be observed with several powder grains between them. After 11 days of hydration, some cracks developed within the pellets due to the decrease of suction. As was observed by Molinero Guerra et al. (2017), cracks were already part of the initial state of the pellet; they appeared during the storage in the laboratory combined to the fabrication process of a single pellet. Those cracks could not be observed in this work, due to the insufficient resolution of the X-ray CT observations (50 $\mu \mathrm{m} / \mathrm{voxel})$ as compared to the resolution that was used to study a single pellet $(4.4 \mu \mathrm{m} /$ voxel $)$; however, it is most probable that they were already present at the initial state and opened while wetting. Wetting induced swelling of smectite particles, enhanced these cracks and made them visible after 11 days of hydration. After 27 days, more cracks were observed, as well as the decrease of the interpellet voids due to swelling. Then, pellets started losing their granular structure. After 56 days, pellets could still be identified even if they had almost lost their initial granular structure; some air-filled inter-pellet voids were observed. Therefore, the evolution of the structure of a single pellet was characterized by the development of cracks combined to the swelling of its components.

Van Geet et al. (2005) investigated the homogenization process of a pellet/powder mixture by performing an analysis of the X-ray CT results. They noticed the decrease of the pellet density while wetting and the final homogenization at complete saturation. In the present work, a vertical section was investigated in order to ensure the total homogenization at the studied resolution along the specimen's height, as well as the sealing of all air-filled voids within the mixture. 


\subsection{Quantitative analyses}

\subsubsection{Evolution of the axial swelling pressure}

The evolution of the axial swelling pressure during wetting was monitored during the test thanks to a force transducer installed at the bottom of the sample (see Figure 1). Results are presented in Figure 4 for the 160 days of hydration. Due to the design of the cell, this value corresponded to the average force transmitted to the porous stone at the bottom of the sample. A plateau of $3 \mathrm{MPa}$ was reached after 100 days of hydration. In the work of Molinero-Guerra et al. (2018), an infiltration column test was performed on the same material with the same conditions. The results showed the same kinetics of the axial swelling pressure (it increased and reached a plateau after 100 days, but at $2.5 \mathrm{MPa}$ ).

After Wang et al. (2012, 2013c), the swelling pressure of pure bentonite, mixture of bentonite/sand, and mixture of bentonite/claystone can be correlated with the dry density of bentonite at the final (fully-saturated) state. A unique equation was proposed to predict the swelling pressure of MX80 bentonite-based materials from the dry density of bentonite. In addition, these works evidenced that the swelling pressure obtained by using synthetic Callovo-Oxfordian claystone water was similar to that obtained by using distilled water due to the low salinity of this synthetic water. Based on the equation proposed by Wang et al. (2012), for a dry density of the mixture of $1.49 \mathrm{Mg} / \mathrm{m}^{3}$ the axial swelling pressure value should equal to 4.15 MPa. This value is higher than those observed in infiltration columns in the present work and in the work of Molinero-Guerra et al. (2018). It is possible that the sample was not completely saturated and the plateau observed did not correspond to the final swelling pressure value.

\subsubsection{Investigation of the displacement field of the bentonite powder}


DVC technique was used to calculate the displacement field of PMMA spheres added to the

248 sample during the fabrication process. Figure 5 presents the results, which correspond to vertical displacements occurring during the first 100 days of hydration (positive value corresponds to an upward displacement; $\mu$ and $\sigma$ represent average and standard deviation values of the displacement, respectively). For each location (height), the displacements of spheres located at $\pm 10 \mathrm{~mm}$ in the vertical direction were considered, and finally the mean value was calculated.

The results show a sudden displacement of $0.2-0.4 \mathrm{~mm}$ of the PMMA spheres towards the bottom after 2 days of hydration for the locations at 30,50, 70 and $110 \mathrm{~mm}$. Actually, these locations correspond to the zone where air-filled inter-pellet voids were dominant (Figure 2). Hydration induced swelling of the material at both ends, increasing the swelling pressure (Figure 4), and provoked pellets re-arrangement. The movement of pellets would then induce the movement of bentonite powder and PMMA spheres located in the inter-pellet voids. As air-filled inter-pellet voids were dominant in these zones, bentonite powder and PMMA spheres would tend to move downward because of gravity. This phenomenon was less visible at $10 \mathrm{~mm}$ from the bottom because the bottom partly restricted this movement. At $90 \mathrm{~mm}$, a heave was observed during the first 2 days of hydration. First, the downward displacement of would have tended to heave to fill the initial gap at the top during these first two days.

The above phenomena continued generally with the same trends until 11 days of hydration. After this date, the movement of the PMMA sphere was negligible until 49 days of hydration. Between 49 days and 56 days of hydration, a sudden downwards movement was found at all the levels (except at $10 \mathrm{~mm}$ from the bottom). This movement might be explained by the movement of the cell during its installation; the cell (the whole system shown in Figure 1a) 
was removed from the microtomograph and put back to its position only during the duration of the scans. This phenomenon might be equally used to explain the general downward displacement between 56 days and 100 days of hydration.

\section{Conclusions}

The wetting-induced structure changes of a pellet/powder bentonite mixture, one of the candidate materials for sealing plugs in deep geological high-level radioactive waste disposal, were investigated in this work by X-ray CT observations.

The results show that the initial mixture was a heterogeneous granular material since the distribution of pellets and powder was not spatially uniform. While wetting the top and bottom sides, water infiltrated quickly into the inter-pellet pores in the vicinity of both hydration fronts. That induced rapid swelling of pellets and powder of bentonite due to the absorption of water by smectite, the principal mineral of bentonite. Firstly, X-ray CT observations showed that the initial granular structure was quickly lost in these zones; pellets lost their structure and the mixture became an apparently homogeneous material, with no more air-filled inter-pellet voids. For the rest of the sample, this process depended on the evolution of the hydration front. Secondly, at the same time, swelling of pellets induced their re-arrangement which caused downward movement of the bentonite powder, induced by gravity, in the zones having large air-filled inter-pellet voids. This phenomenon enhanced the heterogeneous spatial distribution of bentonite powder inside the mixture. Finally, swelling of pellets and the powder grains induced a quick increase of axial swelling pressure that reached $3 \mathrm{MPa}$ after 100 days. This value was lower that the estimated swelling pressure of the same material having identical average dry density after full saturation. This result suggested that the mixture was not fully saturated after 100 days of hydration even if the X-ray CT observations showed a relatively homogeneous structure at this time. 
The results in this study allowed visualizing water infiltration inside the pellet/powder bentonite mixture during hydration. That would contribute to a better understanding on the hydro-mechanical couplings in this material, when it is installed in the real repository.

\section{References}

Alonso, E.E., Romero, E., Hoffmann, C., \& Garcia-Escudero, E., (2005). Expansive bentonite-sand mixtures in cyclic controlled-suction drying and wetting. Engineering Geology, 81(3), pp.213-226.

Bornert, M., Hild, F., Orteu, J.-J. and Roux, S. (2012). Chapter 6: digital image correlation. In: Full-field measurements and identification in solid mechanics. Grediac, M. \& Hild, F. (Eds), Wiley-ISTE, 496 pages

Dixon D. A. Gray M. N. \& Graham J., (1996). Swelling and hydraulic properties of bentonites from Japan, Canada and the USA. Environmental Geotechnics 1, 43-48.

Barnichon, J.D., Deleruyelle, F., (2009). Sealing Experiments at the Tournemire URL. EUROSAFE.

Garcia-Siñeriz, J. L., Villar, M. V., Rey, M., and Palacios, B., 2015. "Engineered barrier of bentonite pellets and compacted blocks: State after reaching saturation," Eng. Geol., vol. 192, pp. 33-45.

Graham, J., Saadat, F., Gray, M. N., Dixon, D. A., \& Zhang, Q. Y., (1989). Strength and volume change behaviour of a sand-bentonite mixture. Canadian Geotechnical Journal 26, No. 2, 292- 305.

Herman, G.T. (1979). Correction for beam hardening in computed tomography. Physicsin Medicine andBiology, 24, 81.

Imbert, C. \& Villar, M.V., (2006). Hydro-mechanical response of a bentonite pellets/powder mixture upon infiltration. Applied Clay Science, 32(3-4), pp.197-209.

Komine, H., \& Ogata, N., (1994). Experimental study on swelling characteristics of compacted bentonite. Canadian geotechnical journal 31 , No. 4, 478-490.

Molinero-Guerra, A., Mokni, N., Delage, P., Cui, Y. J., Tang, A. M., Aimedieu, P., Bernier, F., Bornert, M., (2017). In-depth characterisation of a mixture composed of powder/pellets MX80 bentonite. Applied Clay Science (135), 538 - 546.

Molinero-Guerra, A., Cui, Y.J., Mokni, N., Delage, P., Bornert, M., Aimedieu, P., Tang, A.M., \& Bernier, F., (2018). Investigation of the hydro-mechanical behaviour of a pellet/powder MX80 bentonite mixture using an infiltration column. Engineering Geology, 243, $18-25$. 
Mokni, N. \& Barnichon, J.D., (2016). Hydro-mechanical analysis of SEALEX in situ testsImpact of technological gaps on long term performance of repository seals. Engineering Geology, 205, pp. 81-92.

Pusch, R. (1982). Mineral-water interactions and their influence on the physical behavior of highly compacted $\mathrm{Na}$ bentonite. Canadian Geotechnical Journal, 19(3): 381-387. doi:10.1139/t82-041.

Saba, S., Cui, Y.J. and Barnichon, J.D., (2014). Investigation of the swelling behaviour of compacted bentonite-sand mixture by mock-up tests. Canadian Geotechnical Journal, 51(12), pp.1399-1412.

Sun, W., Sun, D., Fang, L. \& Liu, S., (2014). Soil-water characteristics of Gaomiaozi bentonite by vapour equilibrium technique. Journal of Rock Mechanics and Geotechnical Engineering, 6(1), pp.48-54.

Sutton, M.A., Orteu, J.J., and H. Schreier., H., (2009). Image correlation for shape, motion and deformation measurements: basic concepts, theory and applications. Springer Science \& Business Media.

Van Geet, M., Volckaert, G. \& Roels, S., (2005). The use of microfocus X-ray computed tomography in characterising the hydration of a clay pellet/powder mixture. Applied Clay Science, 29(2), pp.73-87.

Wang, Q., Tang, A.M., Cui, Y.J., Delage, P., Gatmiri, B., (2012). Experimental study on the swelling behaviour of bentonite/claystone mixture. Eng. Geol. 124, 59-66. http://dx. doi.org/10.1016/j.engeo.2011.10.003.

Wang, Q. \& Cui, Y.J., Tang, A.M., Delage, P., Gatmiri, B. and Ye, WM., (2013a). Long-term effect of water chemistry on the swelling pressure of a bentonite-based material. Applied Clay Science. 87. 10.1016/j.clay.2013.10.025.

Wang, Q., Cui, Y. J., Tang, A. M., Barnichon, J. D., Saba, S. \& Ye, W. M., (2013b). Hydraulic conductivity and microstructure changes of compacted bentonite/sand mixture during hydration. Engineering Geology, 164, pp.67-76.

Wang, Q., Tang, A.M., Cui, Y.J., Delage, P., Barnichon, J.D., Ye, W.M. (2013c). The effects of technological voids on the hydro-mechanical behaviour of compacted bentonite-sand mixture. Soils and Foundations, 53(2), 232 - 245.

Wang, Q., Cui, Y. J., Tang, A. M., Li, X. L. \& Ye, W. M., (2014). Time- and densitydependent microstructure features of compacted bentonite. Soils and Foundations, 54(4), pp.657-666. 


\section{List of Tables}

Table 1. Chemical composition of the synthetic water.

\section{$367 \quad$ List of Figures}

368 Figure 1. Photography of the experimental set-up inside the X-ray microtomograph device (b) and layout of the cell (a).

Figure 2. Horizontal sections of the sample at different times and positions obtained by micro-CT. .. 18

373 Figure 5. Vertical displacements obtained by Digital Volume Correlation (DVC) Technique based on 


\section{Tables}

Table 1. Chemical composition of the synthetic water.

\begin{tabular}{|l|l|l|l|l|l|l|l|l|}
\hline Components & $\mathrm{NaHCO}_{3}$ & $\mathrm{Na}_{2} \mathrm{SO}_{4}$ & $\mathrm{NaCl}$ & $\mathrm{KCl}$ & $\begin{array}{l}\mathrm{CaCl}_{2} \\
2 \mathrm{H}_{2} \mathrm{O}\end{array}$ & $\mathrm{MgCl}_{2} \mathrm{O}_{2} \mathrm{H}_{2} \mathrm{O}$ & $\mathrm{SrCl}_{2} 6 \mathrm{H}_{2} \mathrm{O}$ & Total \\
\hline $\begin{array}{l}\text { Mass (g) per } \\
\text { liter of solution }\end{array}$ & 0.28 & 2.216 & 0.615 & 0.075 & 1.082 & 1.356 & 0.053 & 5.677 \\
\hline
\end{tabular}

380

381 
Figure 1. Photography of the experimental set-up inside the X-ray microtomograph device (b) and layout of the cell (a).

(a)

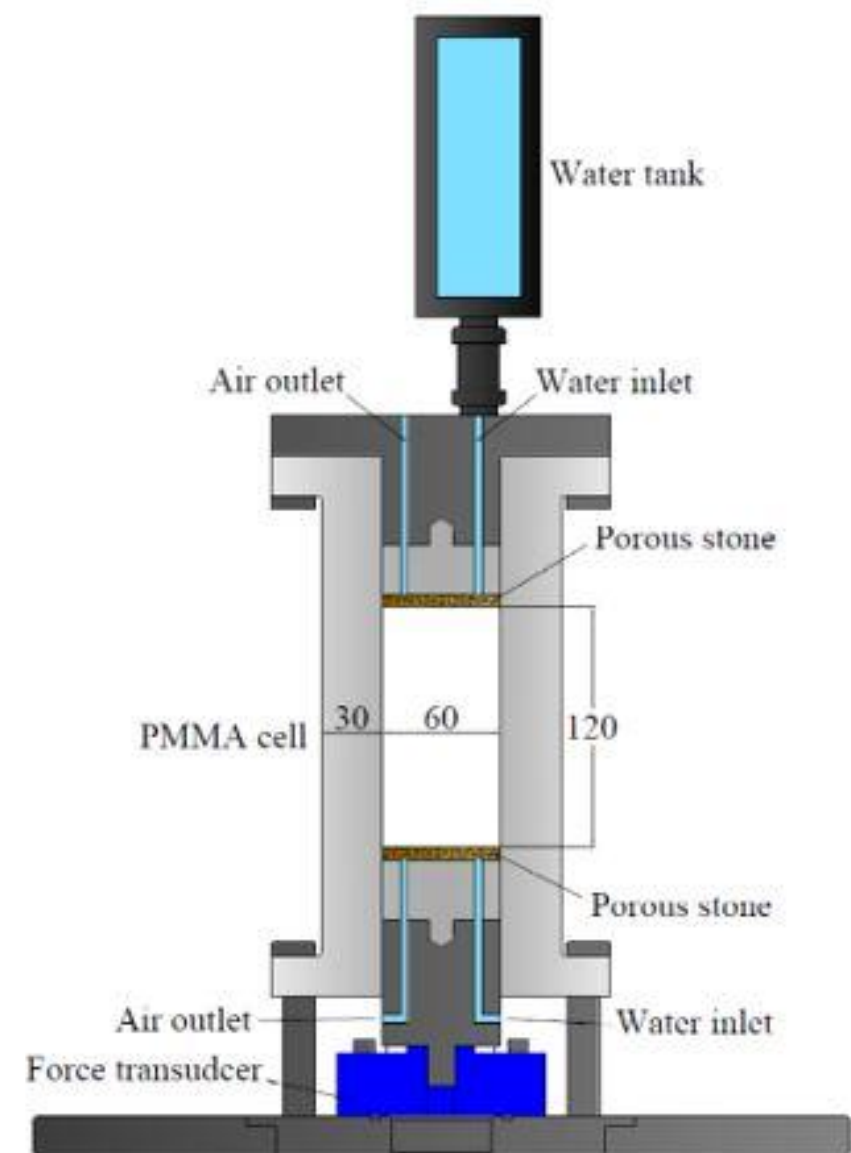

(b)

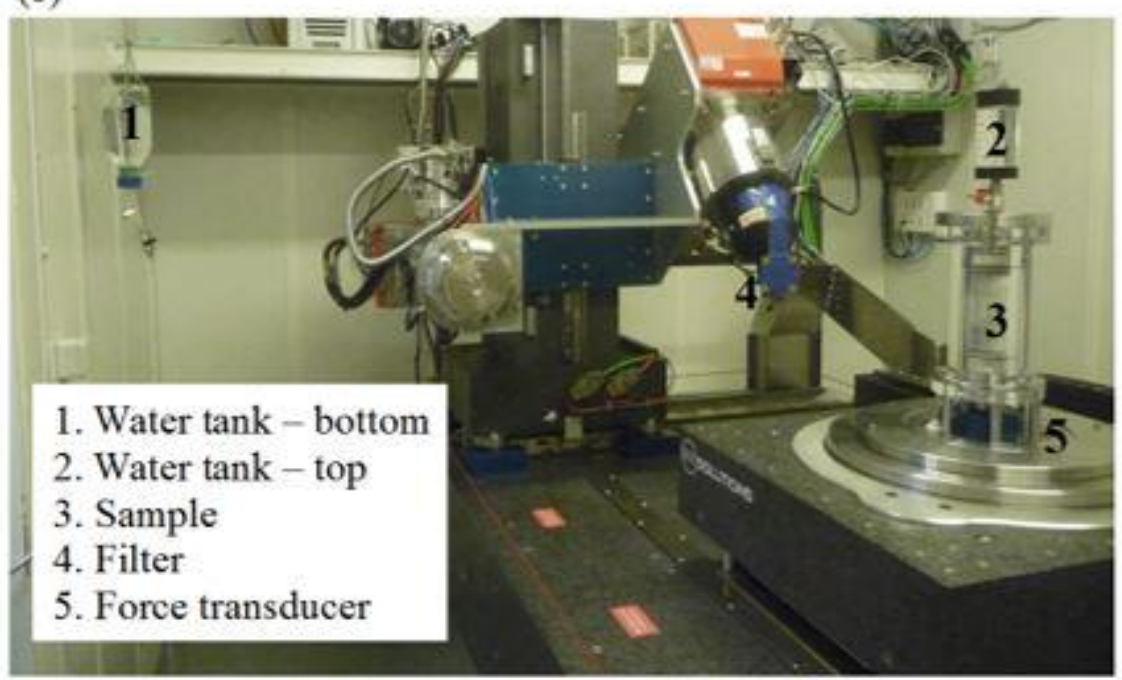


Figure 2. Vertical sections of the sample at different times obtained by X-ray CT.

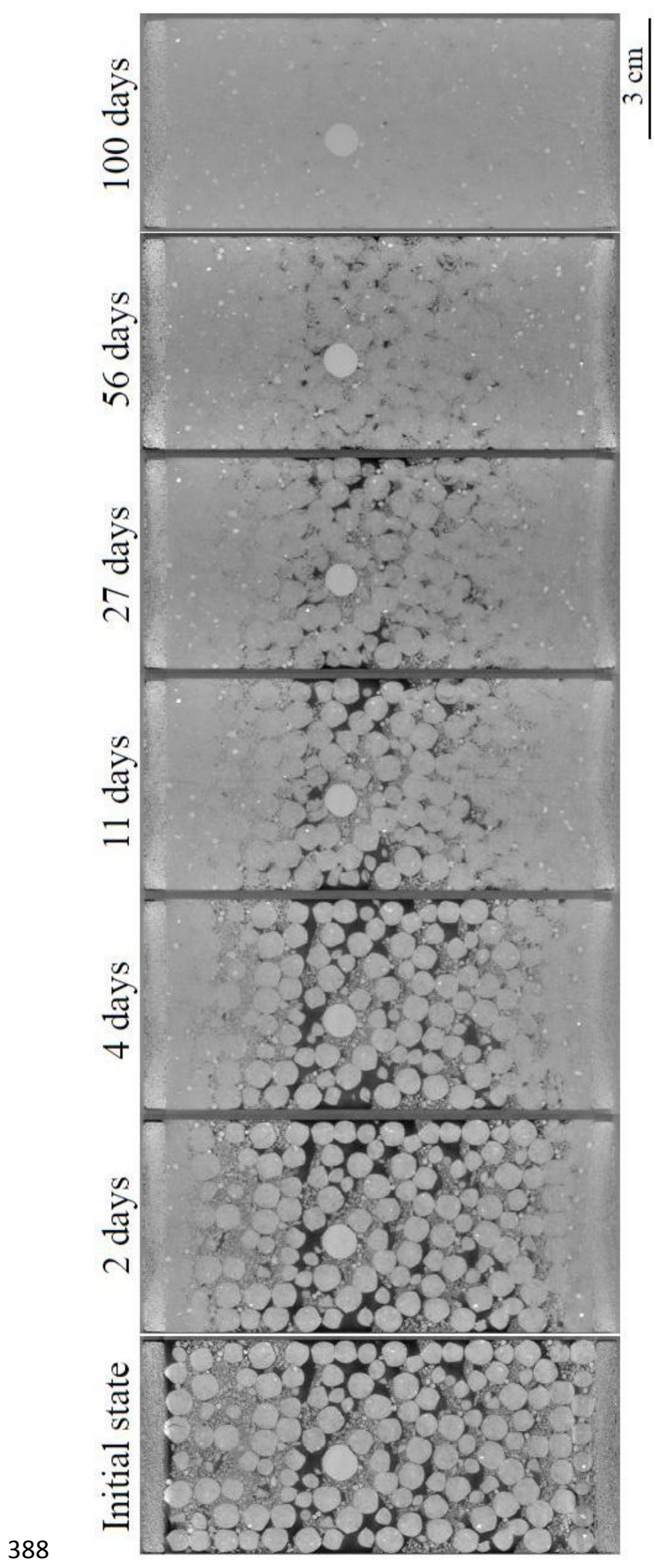


Figure 3. Enlargements of a horizontal section at $60 \mathrm{~mm}$ from the bottom obtained by X-ray CT.
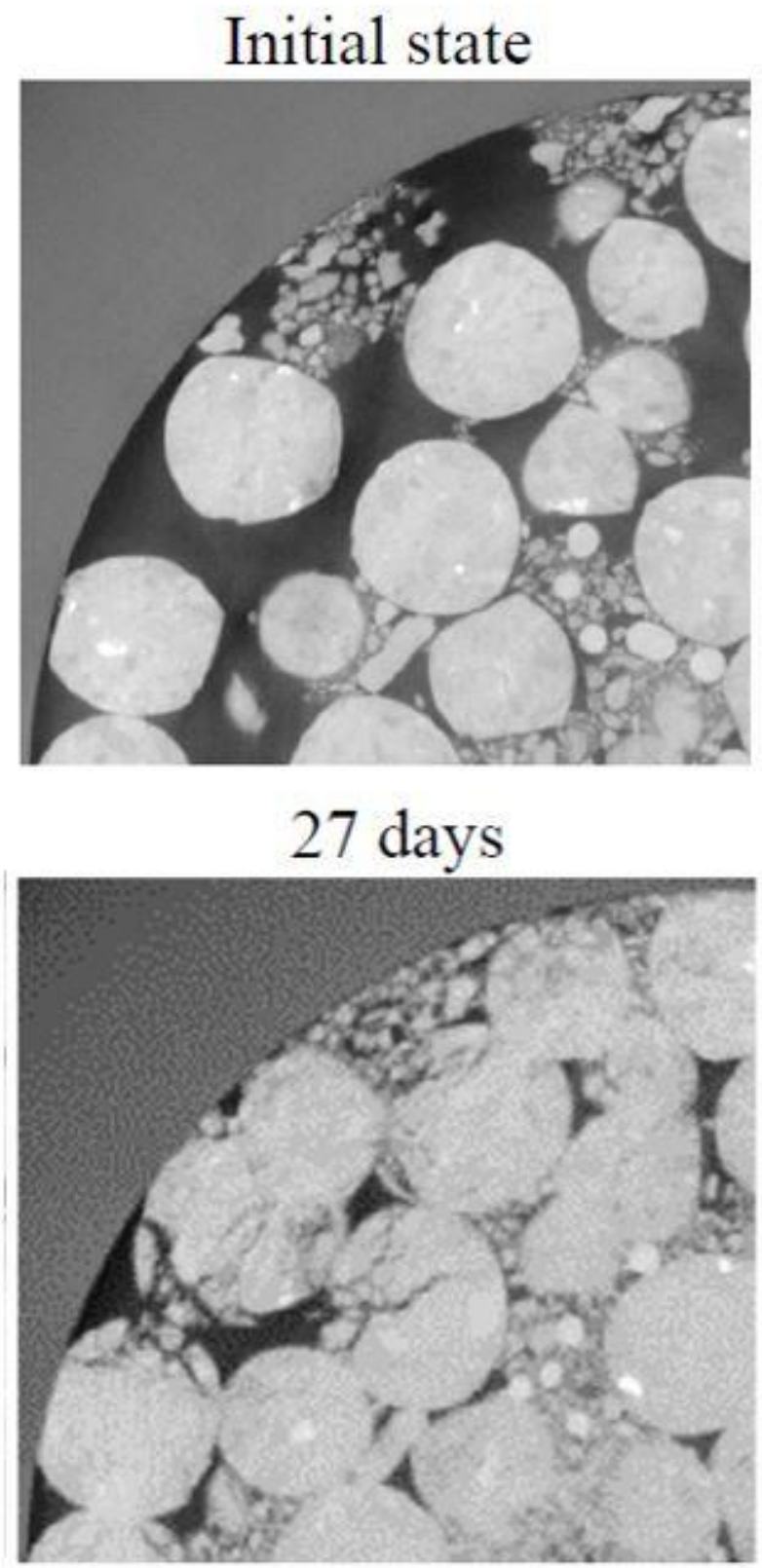

11 days

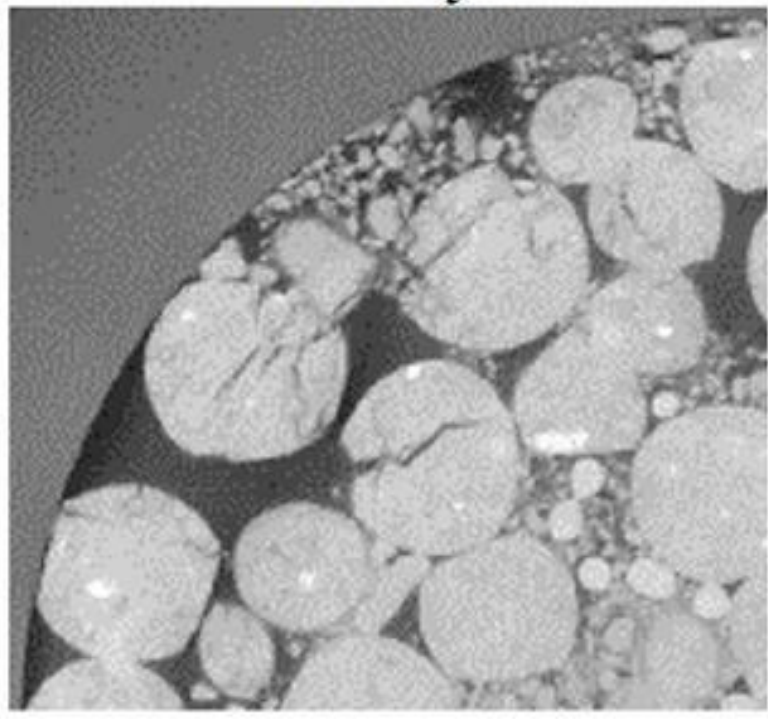

56 days

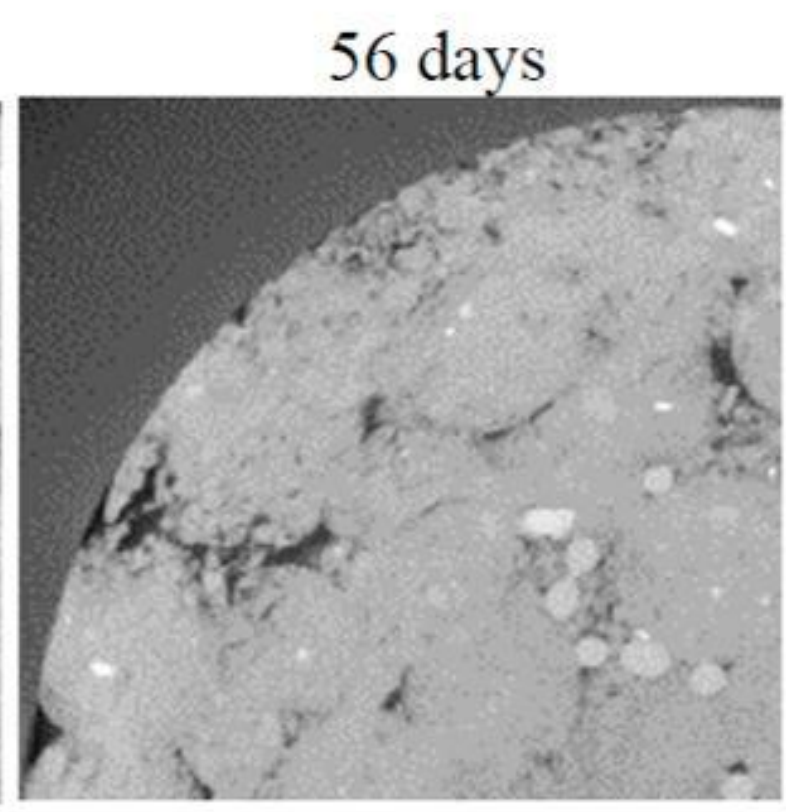


Figure 4. Evolution of the axial swelling pressure of the mixture.

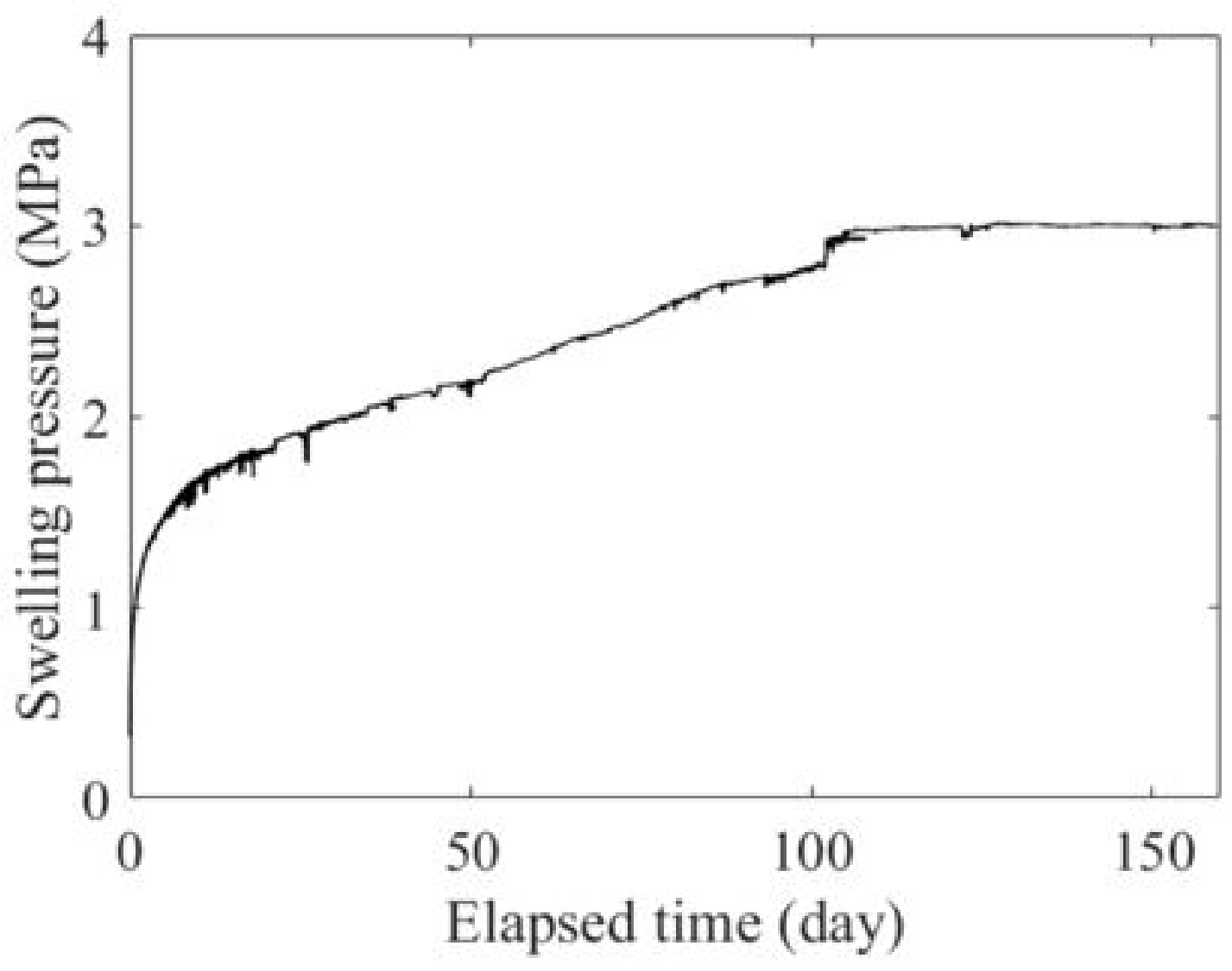

402

403

Figure 5. Vertical displacements obtained by Digital Volume Correlation (DVC) Technique based on the PMMA spheres network while wetting.

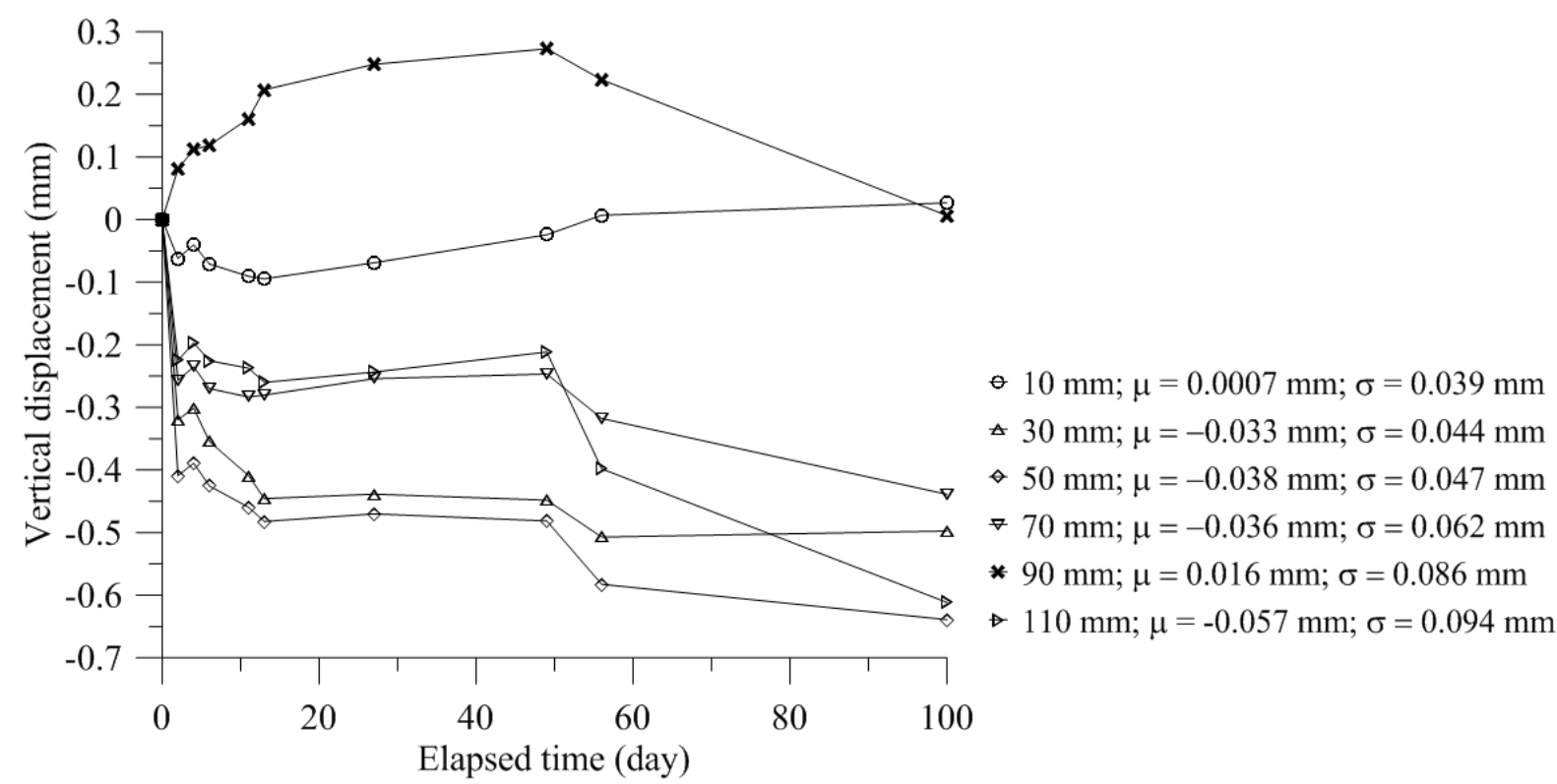

